\section{Eucentric Stage for Recording Stereo Pair Photomacrographs}

\author{
Ted Clarke \\ Metallurgical Failure Analysis Consultant \\ tclarke@ligtel.com
}

The stereo microscope is the most commonly used microscope. This applies to both the materials science and biological science fields. My past career as a materials engineer depended critically upon the three dimensional imaging of the stereo microscope for studying metal parts and fracture surfaces. Unfortunately our clients had no readily available way to view stereo pairs, so stereo
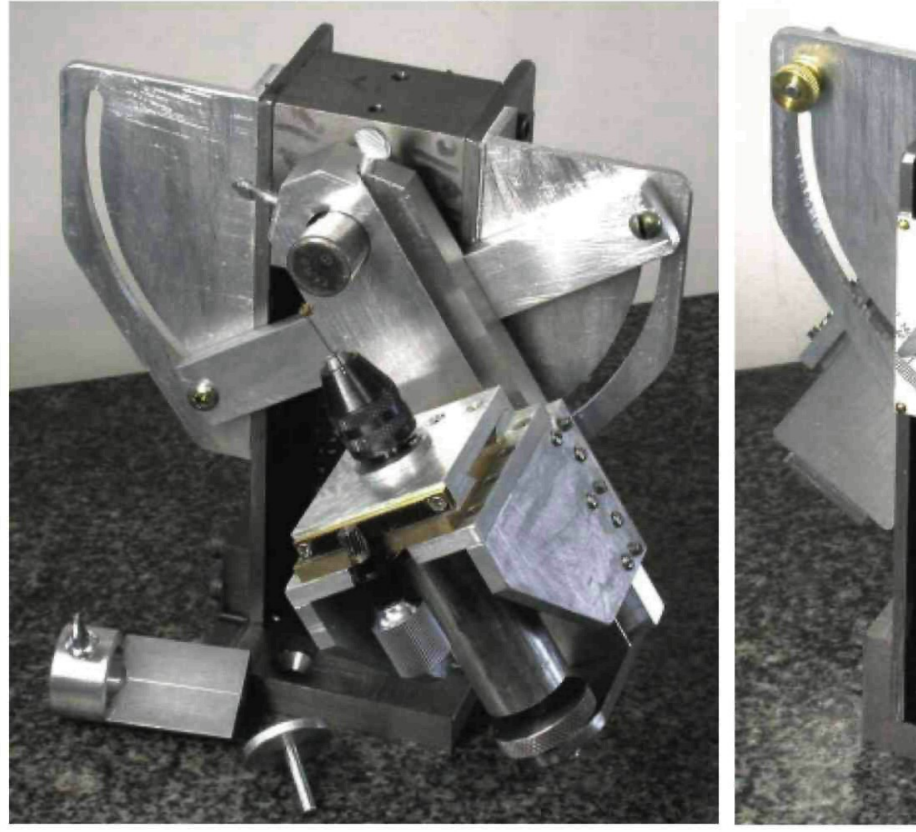

pair recording was not done. Likewise, our electron microscopes were not equipped with costly eucentric stages, which make stereo pair recording easily done. Jan Hinsch has helped me with the historical background on stereo photomacrography. Carl Zeiss offered a Druener camera attachment for their Greenough-style stereo microscope in 1900. More recently, Carl Zeiss, Wild and Nikon have offered sliding monocular tubes for recording either ray path with microscopes using a common main objective. The most recent technology, marketed by Bunton Instrument Co, Inc (www.buntgrp. com) allows video stereo imaging using a PC with live digital images from specially modified stereo microscopes equipped with dual digital cameras. This system serves as a vital training tool for surgeons. It appears that the entertainment industry will have to bring 3D imaging to the mass market, especially with PC based systems, before the technical community can make widespread use of communicating with stereo pair images. I suspect this will be a rapid transition.

Images from my recently completed scanning light photomacrography system convinced me of the need for stereo pair recording capability for this system shown in: http://www. modernmicroscopy.com/main.asp?article $=60$. A simple tilting stage has traditionally been used by scientific photographers. This was not acceptable to me because the region of interest typically moves vertically and laterally when the stage is tilted. It is time-consuming to correct for these unwanted motions, especially when stereo pair recording is not frequently done. My solution was to build the eucentric stage shown in Figure 1 (left). The centering gage with a scribed line, shown on the lower right, is fitted to the spindle end of a water pump bearing. The camera is focused on the line and the stage is translated with the X-Y slides of the macro stand and rotated until the image of the scribed line bisects the field of the camera in the $\mathrm{Y}$ direction and is in sharp focus. The specimen is then placed on the stage and the region of interest is brought into focus by using the vertical and horizontal slides and the rotational axis of the eucentric stage. Figure 2 (right) shows the back of the stage with the protractor and adjustable pointer. Figure 3 shows the first stereo pair recorded with the new stage with a tilt of 12 degrees between views. This stereo pair has been printed with a $60 \mathrm{~mm}$ center to center distance so it can be viewed with the more common viewers, such as the one included with the eighth edition ASM Metals Handbook "Fractography and Atlas of Fractographs." I prefer viewing the separated prints with a large format Geoscope viewer purchased from Berezin Stereo Photography Products at: http://www.berezin.com/3d/viewers1.htm I am willing to work with anyone interested in making the eucentric stage commercially available.

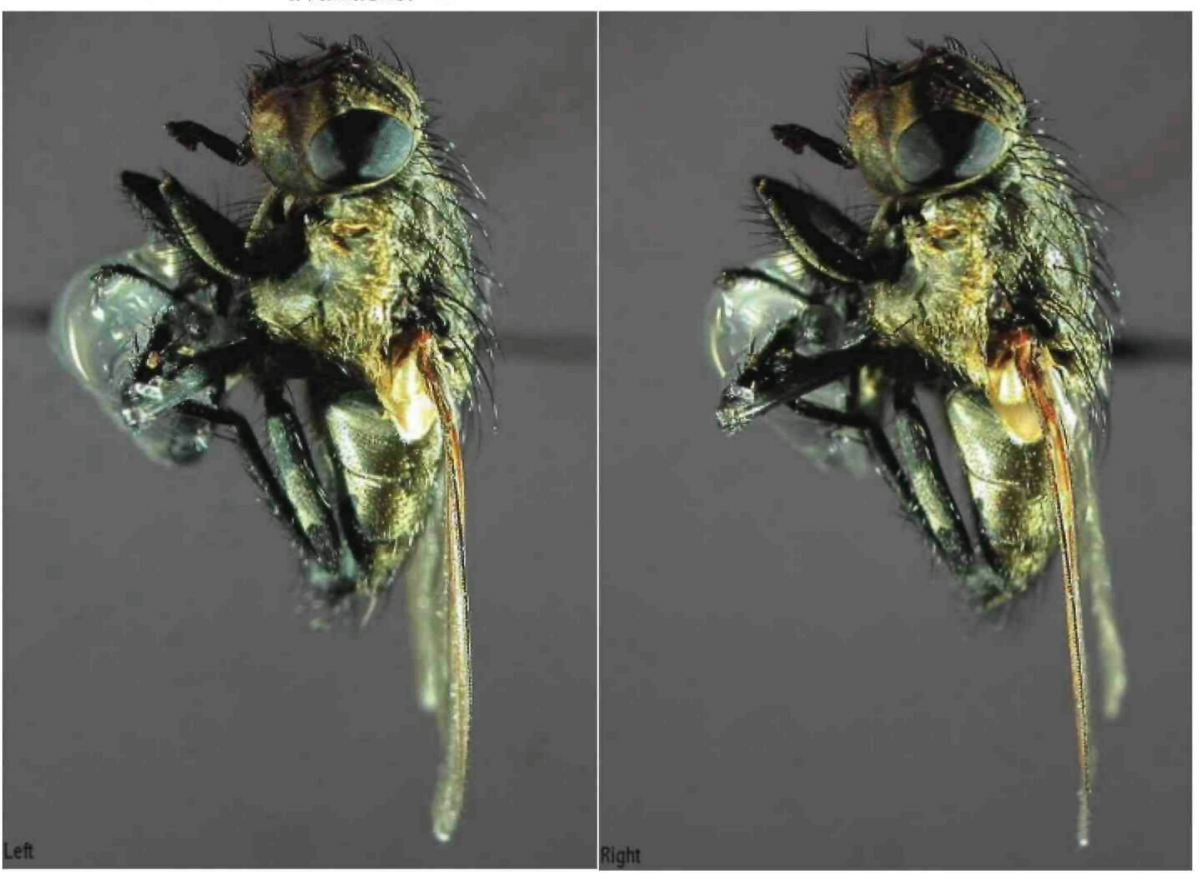




\section{Omniprobe Short-Gut tim brings}

\section{HIAI THROUHHPUT \\ to in-situ TEM sample preparation}

In-Situ FIB Lift-Out

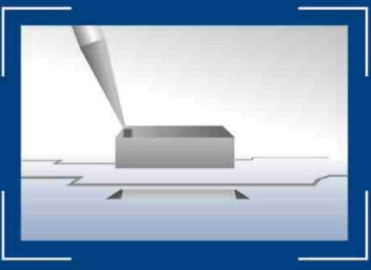

Streamlined in-situ

FIB lift-out with

Omniprobe's

patented Total

Release $^{\mathrm{TM}}$

technology

Mechanical Conversion

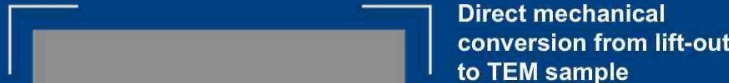

to TEM sample

TEM Sample Prep And

\section{Nano-Mechanical Testing}

The AutoProbe ${ }^{T M} 200$ is a computer controlled in-situ multipurpose nanomanipulator system capable of:

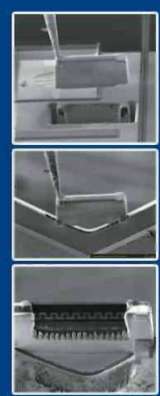

- Lift-out for TEM Sample Prep

- Electrical Measurements

- Nano-Mechanical Testing

Ideal For:

- IC Process Control and

Failure Analyses

- Topographic Surfaces

- Brittle or Soft Materials

- Phase Boundaries

- MEMS Components

$C \in$ and UL certified

Patented Technology

AutoProhe 200
Omniprobe, Inc. 10410 Miller Road Dallas, TX 75238 Phone: $214-572-6800$

Fax: 214-572-6801

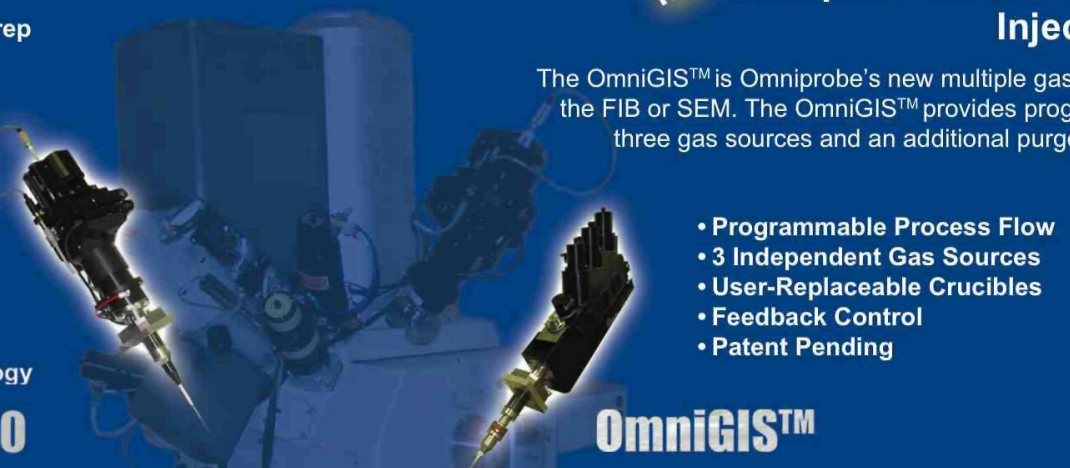

Computer Controlled Multi-Gas Injection System

The OmniGIS ${ }^{\top M}$ is Omniprobe's new multiple gas injection system for

- Programmable Process Flow

- 3 Independent Gas Sources

User-Replaceable Crucibles

Feedback Control

Multiple Gas Sources (Oxide Isolated Pt Via)

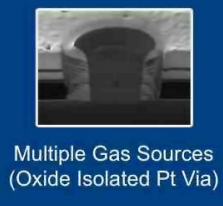

European Support: SEM-FIB Solutions

+441993771203 tony.kendrick@sem-fib.com Oxford, United Kingdom 